HELMUT HASSE - NUMBER THEORY 



\section{NUMBER THEORY}

With 49 Figures

English Translation

Edited and Prepared for Publication

by Horst Günter Zimmer

AKADEMIE-VERLAG - BERLIN 
A corrected and enlarged translation of Hasse, Zahlentheorie, 3rd edition,

(C) Akademie-Verlag Berlin 1969

Erschienen im Akademie-Verlag, DDR - 108 Berlin, Leipziger Straße 3-4 (C) der englischen Ausgabe Springer-Verlag Berlin Heidelberg 1979 Lizenznummer: $202 \cdot 100 / 559 / 79$

Gesamtherstellung: VEB Druckhaus „Maxim Gorki“, 74 Altenburg

Bestellnummer: 7621752 (6296) · LSV 1055

Printed in GDR

DDR 88,- M 